\title{
TEILLIER O LA COMPLEJA SENCILLEZ POÉTICA
}

\author{
Eduardo Llanos Melussa \\ Universidad Diego Portales \\ eduardo.1lanos@udp.cl
}

\section{RESUMEN / ABSTRACT}

La poesía de Teillier constituye una paradoja plena de lecciones. En primer lugar, si bien parece sencilla, oculta una considerable complejidad. Además, fue un lírico neto y nato, que reivindicó sin complejos la provincia y aun la aldea, pero su lirismo alcanza una universalidad indiscutible, al menos en sus mejores poemas; asimismo, en su obra recrea la vivencia y la convivencia, la percepción y la memoria, con ecos tanto del evangelio como de la poesía social. Por último, su generación presenta a la vez un aspecto paradójico, pues es la más notable y diversa, pero permanece insuficientemente explorada. Estas páginas procuran profundizar en las complejidades de Teillier mostrando algunas polaridades que subyacen en su poesía y ciertas peculiaridades antes no estudiadas, y concluyen mostrando la pertinencia de aplicar la epistemología de la complejidad de Edgar Morin.

Palabras ClaVe: Teillier, poesía latinoamericana, epistemología de la complejidad.

Teillier's poetry stands as a paradox bountiful in lessons. Seemingly simple at first sight, it hides considerable complexity. Also, Teillier was a born and pure lyricist, who unabashedly reivindicated the province and the small town, yet his lyricism reaches an unquestionable universality, at least in his best poems; he recreates in his work existence and coexistence, perception and memory, with echoes of both the Gospel and the social poetry. Finally, his generation as a whole presents a paradoxical aspect, as it is the most diverse and noteworthy, but remains insufficiently explored as such. These pages examine the complexities of Teillier's work in depth, showing some of the polarities that underlie his poetry, and certain peculiarities hitherto unstudied, and conclude showing the relevance of applying the Edgar Morin's epistemology of complexity.

KEY WORDS: Teillier, Latin American poetry, epistemology of complexity. 
La generación de Enrique Lihn y Jorge Teillier (llamada del 50 o del 57) merece nuevos estudios, que cuestionen o profundicen los rasgos que hasta ahora se le atribuyen. Se trata de una promoción notablemente diversa (de poetas, narradores, dramaturgos, ensayistas, filólogos y aun filósofos), cuyas contribuciones a las letras iberoamericanas ameritan estudios globales. En esta ocasión, procuraré estudiar la poesía de Teillier, y lo haré deteniéndome en aspectos poco visitados. Mostraré así ciertos patrones fónicos y rítmicos, y las analogías que a partir de allí surgen -como en un fractal-entre diversos niveles: desde el verso al poema, desde el poema al libro, desde cada libro a la obra acumulada. En su aparente "simplicidad" (que no simpleza) subyace una complejidad "formal" e "ideológica" que ha merecido estudios detenidos (sobre todo extranjeros ${ }^{1}$, aunque también algunos nacionales ${ }^{2}$ ). Terminaré el artículo mostrando la pertinencia de aplicar a Teillier algunos principios de la epistemología de la complejidad, de Edgar Morin.

\section{CONDENSACIÓN INICIAL}

Comenzaré destacando que Teillier escribió sus mejores poemas entre los veinte y los treinta y cinco años, y que ellos no parecen corresponderse con la edad real de su autor al momento de escribirlos. Véase "Otoño secreto", que es precisamente el primer poema de Para ángeles y gorriones (1956), volumen inicial (no "primerizo"):

Cuando las amadas palabras cotidianas

pierden su sentido

y no se puede nombrar ni el pan,

ni el agua, ni la ventana,

y ha sido falso todo diálogo que no sea

con nuestra desolada imagen,

aún se miran las destrozadas estampas (2002).

Los más acuciosos son autores de habla inglesa: Niall Binns (2001) y Teresa Stojkov

2 En los años sesenta el poeta concitó muchas reseñas, pero pocos estudios especializados. Entre las excepciones cabe destacar el artículo de Calderón (incluido en Muertes y maravillas), los de Giordano y los prólogos de Binns, Schopf y Lastra en antologías recientes del poeta (consignadas en la bibliografía). 
en el libro del hermano menor, es bueno saludar los platos y el mantel puestos sobre la mesa, y ver que en el viejo armario conservan su alegría el licor de guindas que preparó la abuela y las manzanas puestas a guardar. Cuando la forma de los árboles ya no es sino el leve recuerdo de su forma, una mentira inventada por la turbia memoria del otoño, y los días tienen la confusión del desván a donde nadie sube y la cruel blancura de la eternidad hace que la luz huya de sí misma, algo nos recuerda la verdad que amamos antes de conocer: las ramas se quiebran levemente, el palomar se llena de aleteos, el granero sueña otra vez con el sol, encendemos para la fiesta los pálidos candelabros del salón polvoriento y el silencio nos revela el secreto que no queríamos escuchar.

La engañosa "simplicidad" de estos versos es antesala de su profundidad, y aun la refuerza; pero no sugiere una confianza irrestricta en la comunicación habitual, ni siquiera si ésta se efectúa mediante "las amadas palabras cotidianas", pues en algún momento ellas también "pierden su sentido". Según se desprende del poema, aun la plática más coloquial presupone un periódico recogimiento y una serena reflexión, y si tanto el poeta como todos nosotros descubrimos de pronto la falsedad de ciertos diálogos, ello ocurre cuando la comunicación comienza por encarar "nuestra desolada imagen". Queda así implícita la necesidad de un diálogo interior y, al mismo tiempo, de cierta mediación, pues a lo sumo veremos nuestra imagen, no nuestro ser. Además, aquel mirar pasa luego a "las destrozadas estampas" de un libro y va saludando cosas concretas y cotidianas (platos, mantel, mesa), que finalmente renuevan el contacto y reencantan la existencia porque en su materialidad late la huella humana y familiar. Así, el licor de guindas es la obra cariñosa de la abuela; el armario añoso resume en su propia madera el intercambio creador entre los hombres y la naturaleza, e incluso las manzanas -si bien no son manufacturas- fueron puestas ahí por alguien. Reivindicando la presencia 
efectiva y afectiva de esos objetos, el poeta agrega a la escena hogareña una cierta atmósfera y hasta una cosmovisión: la de una dicha serena, que vincula a las personas consigo mismas, con sus familias, con la comunidad y también con el entorno natural que hace sustentable la vida humana.

Más que mostrar una frontera concebida como paisaje o límite espacial, el poema trasunta una cierta cultura y un modo de vida. De hecho, esta geografía es más humana que física: el otoño tiene memoria, el granero es obra de personas (y además sueña con el sol) y el silencio es comunicante ("nos revela el secreto / que no queríamos escuchar").

Este poema inicial condensa casi todo el resto de la poesía teillierana. En ella latirá luego esa misma sensibilidad, ese mismo amor por la sencillez elemental (el pan, el agua, la ventana) y por la inmediatez cotidiana y familiar. Mientras el poeta permanece en la provincia, su poesía nace de la contemplación afectuosa y agradecida de un mundo inmediato y hogareño ("los lares", según la fórmula acuñada por el propio Teillier) 3; más tarde, trasladado a la capital, su percepción directa del entorno dará paso a la evocación nostálgica de ese mundo perdido.

\section{CARACTERIZACIÓN PRELIMINAR DE LA POESÍA TEILLIERANA}

Reitero: los rasgos recién anotados coexisten ya desde ese primer libro. Véase ahí mismo, por ejemplo, "Puente en el sur":

Ayer he recordado un día de claro invierno. He recordado un puente sobre el río, un río robándole azul al sueño del cielo.

Mi amor era menos que nada en ese puente. Una naranja hundiéndose en las aguas, una voz que no sabe a quién llama, una gaviota cuyo brillo se deshizo entre los pinos.

Ayer he recordado que no se es nadie sobre un puente cuando el invierno sueña con la claridad de otra estación, y se quiere ser una hoja inmóvil en el sueño del invierno, y el amor es menos que una naranja perdiéndose en las aguas, menos que una gaviota cuya luz se extingue entre los pinos.

3 J. Teillier: "Los poetas de los lares", Boletín de la Universidad de Chile, Santiago, No 56, mayo, 1965. Reproducido en Prosas (2000), pp. 21-27. 
Este poema, tan tempranero como el precitado, también encierra casi todos los elementos que luego reconoceremos como típicos de Teillier. Y ya que hacia el final de este artículo se aplicará el principio hologramático de Morin (1990), podemos mostrar desde ya el carácter recursivo de la poesía teillierana si examinamos este poema particular e identificamos ciertas invariantes o rasgos salientes de toda su obra:

\subsection{PREPONDERANCIA DE LA MEMORIA}

Llama la atención que la memoria cobre un valor tan central ya en versos "juveniles". Aparte del inicial "he recordado"-que se repite en el primer verso y reaparece aún en el sexto-, el poema es desde comienzo a fin la evocación de una evocación: el poeta recuerda hoy haber recordado ayer. No es raro entonces que, a la hora de reflexionar sobre el oficio, Teillier plantee que el poeta es el guardián del mito y la memoria colectiva; tampoco es raro que en sus poemas hasta el otoño aparezca dotado de memoria.

\subsection{El PAISAJE MÍtico}

Destaca también la presencia del paisaje y de la naturaleza: "un día de claro invierno", "un puente sobre el río" que roba "azul al sueño del cielo", "una gaviota cuyo brillo se deshizo entre los pinos". Estamos ante un poema 'naturalístico', que al mismo tiempo nos acerca al mito. Así, mientras el cielo duerme, el río le roba azul. Y dado que el azul es símbolo de trascendencia, cabría colegir que el río es otra clase de "puente", que en este caso conduce de lo terrenal a lo celestial, del habitar al trascender, de la percepción sensible a una ascesis contemplativa.

\subsection{Sutileza AFectiva}

Tanto este poema como los demás de Teillier giran en torno al amor, la ternura -no al eros en sus urgencias más crudas- y la amistad, todo ello matizado por connotadores de una tenue melancolía: la naranja se hunde o se pierde en las aguas; el brillo y la luz se deshacen o se extinguen; cierta voz clama sin saber a quién. Y si bien tales actitudes se deben quizás al temple del poeta, también invitan indirectamente a un afinamiento atencional de cada lector. 


\subsection{AutORREVELACIÓN INDIRECTA}

En este poema asistimos a un efecto casi paradójico: el poeta parece desaparecer o disolverse en la propia naturaleza, pero esa desaparición nos lo revela íntimamente: "y se quiere ser una hoja inmóvil en el sueño del invierno, / y el amor es menos que una naranja perdiéndose en las aguas, / menos que una gaviota cuya luz se extingue entre los pinos". Pues bien, ese equilibro entre autodistanciamiento e intimidad será recurrente en toda su poesía.

\subsection{Circularidad}

Ciertas repeticiones y variantes terminan marcando un ritmo y una cosmovisión de carácter cíclico: los primeros dos versos introducen sendas repeticiones ("he recordado" y "He recordado", "el río" y "un río"); además, los tres versos que siguen tienen por tema un sentimiento apenas expresable en imágenes: "Mi amor era menos que nada en ese puente. Una naranja / hundiéndose en las aguas, una voz que no sabe a quién llama, / una gaviota cuyo brillo se deshizo entre los pinos". Y así como en una pieza musical percibimos un tema y sus variaciones, casi toda la segunda estrofa es una variante de la primera: si en el cuarto verso la naranja está "hundiéndose en las aguas", en el penúltimo aparece "perdiéndose en las aguas". Y también hay matices en esa gaviota que sobrevuela los versos finales de ambas estrofas: en el primer caso, su "brillo se deshizo entre los pinos", mientras en el segundo su "luz se extingue entre los pinos".

\subsection{FRONTERA Y COLINDANCIA}

Por concreto que sea el puente evocado, refuerza el carácter fronterizo: un puente siempre supone unión entre dos o más zonas (reales o simbólicas), y evoca por ello la idea de tránsito. Asimismo, por material que sea el río evocado, también connota tránsito, dinamismo y proceso. Así, pues, la poesía de Teillier es fronteriza en diversos sentidos y en varios niveles.

\subsection{Clausura y apertura}

La circularidad y el espiral hacen que este poema se cierre sobre sí mismo con naturalidad, como sin esfuerzo ni deliberación. Reencontraremos esa misma circularidad presidiendo cada libro y, hasta cierto punto, parece corresponder a una actitud existencial e incluso a un verdadero destino 
poético. Sin embargo, esa redondez formal no equivale a un cierre, sino a una apertura, pues invita a una relectura periódica, que termina incorporando al lector a esa dimensión cíclica.

\subsection{Permanencia y tRansición}

Ya su primer título, Para ángeles y gorriones, insinúa un tránsito y al mismo tiempo cierta continuidad entre naturaleza (gorriones) y espíritu (ángeles), un ámbito común y un vuelo fluido entre lo cotidiano y lo sagrado. Sin embargo, la obra final del poeta parece sugerir que tal continuidad resultará casi insostenible en el mundo apoético, es decir, el situado fuera del entorno protegido de la infancia, la provincia y la atmósfera mítica. A este doloroso cambio - provocado por el nuevo contexto histórico- Binns (2001) lo llama acertadamente "la tragedia de los lares".

En todo caso, el poeta sobrellevará dicha tragedia sin rendirse.

\section{PERSISTENCIA Y EVOLUCIÓN}

Pese a la precocidad y la fluidez de su talento poético, Teillier no es un espontaneísta. En Muertes y maravillas -temprana antología que él mismo pergeñó a los treinta y cinco años-introdujo modificaciones considerables en un buen número de poemas juveniles, y otro tanto hizo en Para un pueblo fantasma (1978). Por cierto, tales enmiendas (en su mayoría felices) revelan autocrítica y una conciencia estética progresiva, propia de quien toma en serio su oficio.

Sin embargo, el plano "formal" de la poesía de Teillier sigue mereciendo mayor atención de la crítica. Sí: su léxico resulta casi siempre sencillo, sus versos suelen ser breves y las imágenes remiten a menudo a una cotidianidad aparentemente inmediata; pero conviene ponderar otras peculiaridades. Para empezar, y aunque no se lo propusiera programáticamente, Teillier se mantuvo proclive a ciertas variaciones; sin distanciarse de su esencia, fue capaz de diversificarse. Por ejemplo, cultivó el poema largo -Los trenes de la noche (1964), Crónica del forastero (1968), Treinta años después [1968]-, género al que parecía inclinarse por su temple pausado, propenso a los retornos y las variaciones en espiral (en Teillier es frecuente una especie de ritornello). Al mismo tiempo, y sin que ello genere contradicción, aprovechó una cierta facilidad natural para el poema breve y aun brevísimo, acercándose a veces 
a la poesía oriental, registro al que propendía por motivos también naturales (la agudeza de su mirada, su atención al entorno próximo, la nitidez de su intuición). Tomaré dos ejemplos de Poemas del país de Nunca Jamás (1963); el primero se titula "Recuerdo de un domingo":

Un gato y una mariposa

peligrosamente cerca.

Pero el viento no duerme.

Véase ahora este segundo ejemplo, titulado "Invierno":

Una luz en el patio.

Y de la mano sorprendida de la noche

se desliza un murciélago.

Desde luego, estos poemas tienen la misma longitud (tres versos); pero las similitudes van ciertamente más lejos. Para empezar, los dos parten de una percepción visual, que refuerza la impresión de estar ante el apunte de alguien alerta al aquí y al ahora inmediatos. En ambos casos los versos giran desde la percepción a la imaginación y desde la descripción a la metáfora: en el primero, el viento aparece implícitamente animado y vigilante ("no duerme"); en el segundo, la noche está personificada: tiene una "mano" (no una garra), que a su vez está "sorprendida". Finalmente, en cada uno de estos poemas algo vuela (una mariposa, un murciélago) y nos remite así al elemento aire, mientras un fenómeno natural (el viento en el primero, la noche en el segundo) está animado y nos reenvía a la tierra. Esa contraposición de lo aéreo y lo terrenal se corresponde además con una sutil dialéctica entre la actitud contemplativa y el compromiso existencial.

La mixtura del lenguaje literal y el figurado -observación de hechos e insinuaciones con aire de parábola- se hará luego recurrente en la sección "Cosas vistas", que en Muertes y maravillas consta de 38 fragmentos y que en Para un pueblo fantasma (1978) aumenta a 50. En algunos de estos fragmentos (el 3, por ejemplo) predomina la naturaleza: Con el grito amarillo / del aromo / se despierta la mañana. En otros casos $(8,42)$ la naturaleza es un entorno en que el ser humano -niño o adulto, vivo o muerto- se vuelve trascendente:

Las primeras luciérnagas: 
un niño corre a buscarlas para su amigo enfermo.

Fuego bajo las cenizas.

$\mathrm{Y}$ en el muro

la sombra de los amigos muertos.

En el fragmento 8 la trascendencia opera por una acción solidaria; en el fragmento 42 la capacidad evocadora fusiona lo patente (cenizas) y lo latente (fuego), la percepción y la intuición, la realidad y el símbolo, este mundo y el otro. Por otra parte, habiéndose publicado cinco años después del golpe militar, "la sombra de los amigos muertos" admite también una lectura en clave política (dimensión de la cual Teillier nunca se enajenó) ${ }^{4}$.

\section{EL PLANO FÓNICO}

Teillier no escribió con métrica regular ni con rima. En esto resulta más semejante a Gonzalo Rojas ${ }^{5}$ y se distingue claramente de Lihn y Parra, quienes escribieron algunos sonetos u otras formas convencionales (a veces para desafiarlas y transgredirlas). Claro está que en estos versos sí aparece con relativa frecuencia una rima interna reiterada, que acaso en otros contextos generaría un retintín incómodo, pero que aquí está al servicio del ritmo y de cierta eufonía. Sin ir más lejos, repasemos los poemas ya citados. En "Puente en el sur" se triplica la dupla $i-o$ : "una gaviota cuyo brillo se deshizo entre los pinos". En "Otoño secreto" vuelve a triplicarse una dupla (esta vez $a-a$ ): "Cuando las amadas palabras cotidianas", y ese mismo poema prolonga la recurrencia del fonema $a$ ("ni el $a \mathrm{gu} a$, ni la ventana", "las destrozad $a$ s estampas"), recurrencia que se intensifica como un eco subliminal con

\footnotetext{
$4 \quad$ Véase "A mi madre", de Hotel nube (1996), en que alude al exilio familiar, o "Adiós al Führer".

Teillier y Rojas comparten también la tendencia a publicar libros en espiral, que recogen poemas inéditos junto a otros ya conocidos. Además, ambos nacen en pequeñas ciudades del sur, ambos se vienen a estudiar pedagogía en Santiago y ambos rechazan explícitamente la impostura capitalina. En esto están más cerca de Neruda, mientras que Parra y Lihn parecen más próximos al perfil de Huidobro.
} 
numerosos vocablos: "desolada", "las manzanas", "invent $a \mathrm{~d} a$ ", "las ramas", "pálidos candelabros". Paradójicamente, ese texto casi audible termina por remitirnos a un contexto silencioso, al que sin embargo tampoco hubiéramos llegado por otra vía: “[...] y el silencio nos revela el secreto / que no queríamos escuchar".

Por un lado, estas asonancias y aliteraciones pudieran ser meramente casuales; por otro lado, su abundancia induciría a creer que son deliberadas. Pero conjeturar lo primero o lo segundo no resulta necesario ni conducente; lo relevante es que, sea espontáneo o deliberado, este rasgo estilístico es casi sistemático. En E1 árbol de la memoria (1961) hay un poema que comienza así (destaco con cursivas las asonancias más notorias): "Vimos llegar mañanas / que eran bandadas de grullas / con maravillas en las pupilas / y las seguimos a puertos olvidados". Tantas reiteraciones $(a-a, l l-l l, i-i) i$ no piden acaso una lectura o relectura más atenta? De hecho, el fenómeno se reitera de inmediato: "Allí nos esperaban muchachas descalzas [...]", "reuniendo gavillas de islas amarillas", "la lluvia encontrará caminos desconocidos" (nótese la recurrencia del sonido con- y de la asonancia $i-o$ ). Incluso en un poema tan vivencial como "Despedida", los primeros cuatro versos presentan quintuplicada la asonancia $a-o$ ("Me despido de mi mano / que pudo mostrar el paso del rayo / o la quietud de las piedras / bajo las nieves de antaño"), asonancia que asoma aisladamente después ("blanco", "confiado", "verano") y reaparece por partida doble en el verso final ("que respiramos y dejamos de respirar"). En el mismo poema cabe notar la asonancia $i$-o ("ríos perezosos", "molinos vacíos", "me despido de los amigos", "vino", "sino", "conmigo"), y también las asonancias $e-a$ y $a-e$, en un auténtico vaivén ("cualquier $a$ tarde de esas en que las calles se llenan / de humaredas de hojas quemándose en las acequias"; "y me despido de estos poemas"). Asimismo, se multiplica la dupla e-o ("cuyo rostro suelo ver en sueños", "estos", "verdadero"), y desemboca en la asonancia $a-a$ ("muchacha", "si la amaba o no la a maba", "mirad a", "nostalgia", "agua", "palabras, palabras"). Definitivamente, aunque haya pasado inadvertida, esta tendencia resulta tan recurrente en Teillier, que agregar otros ejemplos costaría muy poco.

\section{EL LÍRICO COMO MÉDIUM ENTRE MUNDO Y TRASMUNDO}

Teillier sabe muy bien qué voces escuchar y cuáles desoír. Su obra cursa al margen no solo del artificio poeticoide, sino incluso de la tradición más 
valiosa y notoria de la poesía castellana. De seguro conoce bien tal acervo -acaso tanto como Arteche o Hahn-, pero casi no resuena en su escritura. Es como si creyera que cualquier intromisión de las convenciones del oficio pudiera restar fluidez y naturalidad a su escritura, y aun a su condición de poeta esencial. Aunque seguro de sus raíces, o precisamente por eso, parece más confiado en el poder anónimo de la revelación que en sus destrezas personales: "Yo debía transformarme en una especie de médium para que a través de mí llegara una historia, y una voz de la tierra que es la mía, y que se opone a la de esta civilización cuyo sentido rechazo y cuyo símbolo es la ciudad en donde vivo desterrado, sólo para ganarme la vida, sin integrarme a ella, en el repudio hacia ella"6.

Fiel a sus ancestros y a su voz interior, este lírico responde solo a las interpelaciones de lo genuino y lo trascendente, sin importar de qué dimensión provengan. "Para hablar con los muertos" (Muertes y maravillas, pp. 46-47) es claro ejemplo de todo ello:

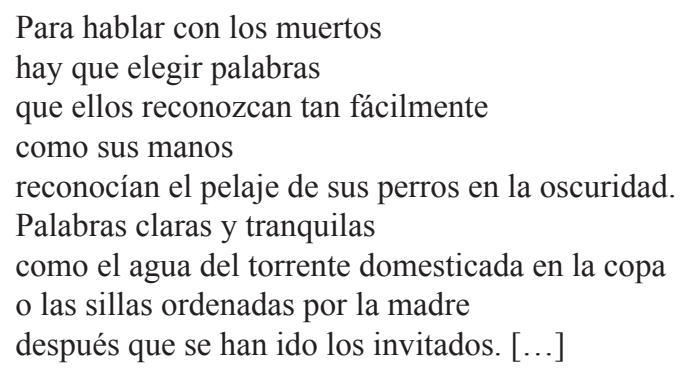

Un poema de esta índole es compatible con cualquier credo, pues no constituye una declaración confesional. Más bien sugiere una religiosidad natural (acaso la única que garantizaría una cierta paz mundial, ya que no parece amenazante para nadie y en cambio podría resultar compartible para todos). Religiosidad que, por otra parte, tampoco consiste en abandonar este mundo ni en negar la realidad de los sentidos. Al contrario: esa comunicación con los muertos no se hará en el más allá, sino en unas circunstancias humanas y terrenas, aunque sublimadas mediante palabras sencillas, que para los difuntos serán tan reconocibles "como el pelaje de sus perros en la oscuridad". A su vez, los

\footnotetext{
6 Sin desmentir lo anterior, Teillier hizo después declaraciones casi opuestas. Ver Entrevistas (1962-1996).
} 
muertos responderán con señales sensibles: con una hoja de álamo atrapada por un espejo roto, / con una llama de súbito reanimada en la chimenea, / con un regreso de pájaros oscuros. Y el sonido refuerza una vez más el sentido, pues esas apariciones fantasmales y repentinas están asociadas a tres esdrújulas ("álamo", "súbito", "pájaros”), que se agrupan hacia el final en versos seguidos.

\section{CRISTIANISMO, COOPERATIVISMO Y COMUNALISMO}

A partir de su título, se podría esperar que "Retrato de mi padre, militante comunista" se situara en el polo opuesto del poema recién citado. Mal que bien, el comunismo histórico - para distinguirlo del comunismo utópico o comunalismo- no solo fracasó, sino que en muchos casos mantuvo regímenes dictatoriales y sangrientos; por lo mismo, ya la propia palabra "comunista" tiene para muchos connotaciones ingratas. Sin embargo, en este poema la profunda humanidad del retrato termina casi sacralizando la realidad aludida. He aquí el poema completo, pues vale la pena apreciarlo como globalidad:

En las tardes de invierno

cuando un sol equivocado busca a tientas

los aromos de primaveras perdidas,

va mi padre en su Dodge 30

por los caminos ripiados de la Frontera

hacia aldeas que parecen guijarros o perdices echadas.

O llega a través de barriales

a las reducciones de sus amigos mapuches

cuyas tierras se achican día a día,

para hablarles del tiempo en que la tierra

se multiplicará como los panes y los peces

y será de verdad para todos.

Desde hace treinta años

grita "Viva la Reforma Agraria"

o canta "La Internacional"

con su voz desafinada

en planicies barridas por el puelche, en sindicatos o locales clandestinos, rodeado de campesinos y obreros, maestros primarios y estudiantes, 
apenas un puñado de semillas

para que crezcan los árboles de mundos nuevos.

Honrado como una manta de Castilla

lo recuerdo defendiendo al Partido y la Revolución

sin esperar ninguna recompensa

así como Eddie Polo -su héroe de infancia-

luchaba por Perla White.

Porque su esperanza ha sido hermosa

como ciruelos florecidos para siempre

a orillas de un camino,

pido que llegue a vivir en el tiempo

que siempre ha esperado,

cuando las calles cambien de nombre

y se llamen Luis Emilio Recabarren o Elías Lafertte

(a quien conoció una lluviosa mañana de 1931 en Temuco,

cuando al Partido sólo entraban los héroes).

Que pueda cuidar siempre

los patos y las gallinas,

y vea crecer los manzanos

que ha destinado a sus nietos.

Que siga por muchos años

cantando la Marsellesa el 14 de julio

en homenaje a sus padres que llegaron de Burdeos.

Que sus días lleguen a ser tranquilos

como una laguna cuando no hay viento,

y se pueda reunir siempre con sus amigos

de cuyas bromas se ríe más que nadie,

a jugar tejo, y comer asado al palo

en el silencio interminable de los campos.

En las tardes de invierno

cuando un sol convaleciente

se asoma entre el humo de la ciudad

veo a mi padre que va por los caminos ripiados de la Frontera

a hablar de la Revolución y el paraíso sobre la tierra

en pueblos que parecen guijarros o perdices echadas.

Por calidad y calidez, por su sensibilidad verbal y social, este homenaje al padre puede compararse a "Carbón", de Gonzalo Rojas (curiosamente, en ambos poemas el padre viste manta de Castilla). Insospechadamente, en sus versos laten claves cristianas: la predicación ante los humildes, el milagro de la multiplicación de los panes y los peces, una tierra prometida para todos. Por 
cierto, se nombra explícitamente la militancia comunista del padre, pero se lo muestra promoviendo el desarrollo comunitario antes que la agitación social. Por lo demás, la militancia paterna remite a una época digna de nostalgia: "cuando al Partido sólo entraban los héroes", lo que de paso insinúa que el comunismo tuvo luego militantes que no estaban a la altura de su propia tradición. Y aunque tal contraste quede implícito y no resulte agresivo, tampoco es ambiguo. Por otra parte, las virtudes del padre coinciden con las grandes virtudes teologales (fe, esperanza, amor); sin embargo, ello no redunda en una efigie "edificante" ni "deificante", y el propio poeta muestra respecto al padre ternura antes que orgullo. De hecho, el poema semeja una rogativa: "Porque su esperanza ha sido hermosa / como ciruelos florecidos para siempre / a orillas de un camino, / pido que llegue a vivir en el tiempo / que siempre ha esperado".

Esta evocación proyecta un pasado irrecuperable al fusionarlo con un futuro utópico. Apuntando tanto hacia el triunfo de la justicia social (promesa de la Revolución) como hacia la paz espiritual ("el paraíso sobre la tierra"), el poeta refuerza su homenaje en verso con una suerte de plegaria. El padre aparece entonces como un hombre amigable, una especie de líder rural de buen humor y hasta de buen apetito, atento a las relaciones de camaradería y a los vínculos familiares; en suma, se retrata a un hombre de buena voluntad.

Ahora bien, en un plano macrosocial y macropolítico, ¿no es precisamente esa "buena voluntad" el ideal en que confluyen las utopías comunalistas y el cristianismo, más allá de sus innegables diferencias doctrinarias? Esta conclusión se refuerza además con otro hecho relevante: la escasa poesía "política" o "social" de Teillier está impregnada siempre de una empatía entrañable, a mucha distancia de la rabia destemplada e incluso de la indignación legítima. Si no escribió poesía religiosa confesional, tampoco cultivó la poesía partisana; simplemente, sintonizó con verdades esenciales, por encima de banderías excluyentes. 


\title{
7. NOSTALGIA DE FUTURO
}

Si en Teillier la polémica resulta apenas ocasional, es porque sus poemas apuntan casi invariablemente hacia una cotidianidad trascendente. "Fin del mundo", de Poemas del País de Nunca Jamás, ilustra con nitidez esta actitud:

\author{
El día del fin del mundo \\ será limpio y ordenado \\ como el cuaderno del mejor alumno. \\ El borracho del pueblo \\ dormirá en una zanja, \\ el tren expreso pasará \\ sin detenerse en la estación, \\ y la banda del Regimiento \\ ensayará infinitamente \\ la marcha que toca hace veinte años en la plaza. \\ Sólo algunos niños \\ dejarán sus volantines enredados \\ en los alambres telefónicos, \\ para volver llorando a sus casas \\ sin saber qué decir a sus madres \\ y yo grabaré mis iniciales \\ en la corteza de un tilo \\ pensando que eso no sirve para nada. \\ Los evangélicos saldrán a las esquinas \\ a cantar sus himnos de costumbre. \\ La anciana loca paseará con su quitasol. \\ Y yo diré: "El mundo no puede terminar \\ porque las palomas y los gorriones \\ siguen peleando por la avena en el patio".
}

Prima facie, estaríamos de nuevo ante un poema sencillo y "claro"; pero una segunda lectura nos revelará complejidades inesperadas. Para empezar, admite dos interpretaciones opuestas: [1] cabría asumir que la intuición del poeta es correcta y que el fin de mundo es una falsa alarma, desmentida por la vitalidad con que palomas y gorriones siguen disputándose como siempre la avena en el patio; [2] al mismo tiempo, cabe concluir lo inverso: si el fin del mundo sobrevendrá un día cualquiera, el 'vate' no podrá 'vaticinarlo', precisamente porque no habrá señales que permitan presagiarlo. 
En un tercer nivel, notamos que la situación resulta indecidible. Y aceptando esa indecibilidad, posibilitamos una nueva esperanza. Así, se engañe o no el poeta al apostar por la supervivencia de la humanidad y del ecosistema todo, descubrimos que su opción es razonable y aun sabia, similar a una versión laica de la célebre apuesta pascaliana.

En un cuarto nivel, comprobamos que la poesía de Teillier trasmite ese optimismo sutil, que prevalece por encima del aire melancólico y nostálgico de muchos de sus versos, o incluso en coexistencia con tales sentimientos.

Algo similar ocurre en "Edad de oro", de El cielo cae con las hojas (1958):

Un día u otro

todos seremos felices.

Yo estaré libre

de mi sombra y mi nombre.

El que tuvo temor

escuchará junto a los suyos

los pasos de su madre,

el rostro de la amada será siempre joven

al reflejo de la luz antigua en la ventana,

y el padre hallará en la despensa la linterna

para buscar en el patio

la navaja extraviada. [...]

Como se ve, este poema apunta explícitamente a un tiempo mítico; sin embargo, invirtiendo el tópico, la edad de oro no remite aquí al pasado, sino al porvenir. Teillier lo dijo de modo muy nítido: "Nostalgia sí, pero de futuro, de lo que no nos ha pasado, pero debiera pasarnos". Ahora bien, si reflexionamos respecto a qué porvenir alude el poema, surge otra paradoja. En principio, se refiere a un futuro de reencuentro humano: "nos reuniremos" "y nos saludaremos". Pero ocurre que habrá unas presencias superiores, pues estaremos "bajo" su mirada: [...] Todos nos reuniremos / bajo la solemne y aburrida mirada / de personas que nunca han existido, / y nos saludaremos sonriendo apenas, / pues todavía creeremos estar vivos.

Todo sugiere, pues, que en el poema confluyen al menos tres niveles de existencia y temporalidad diversos y aun opuestos: [1] el aquí-ahora histórico en que aún no somos felices; [2] un futuro (o más bien futurible) en que si seremos felices; [3] una dimensión trascendente en que no se es ni feliz ni infeliz, y de la que ni siquiera nos percataremos, "pues todavía creeremos estar vivos". Para colmo de paradojas, ingresaremos a esa tercera dimensión 
de modo casi espectral, y allí otros seres no menos fantasmales que nosotros nos mirarán con una extraña mezcla de solemnidad y aburrimiento. Es decir, los mundos posibles podrán interpenetrarse, pero sin confundirse.

\section{ALGUNOS REPAROS FORMALES}

He puesto de relieve diversos valores éticos y estéticos de la poesía de Teillier. En ese contexto de admiración, confieso también que el rigor verbal no me parece su mérito principal, y reiteraría algo similar sobre la artesanía del ritmo y la sintaxis. Cualquiera podrá discrepar de estos juicios, y si ofrece contraargumentos, será un debate razonable y enriquecedor; pero abdicaríamos del discernimiento crítico si nos desentendiéramos de los ripios considerándolos opciones deliberadas. Por ejemplo, ¿son descuidos formales o aciertos los versos finales de "Por última vez" (Muertes y maravillas, 1972, p. 42)?
[...] Las ruedas del tren me repetían esa frase
y yo me desperté cerca del pueblo
que no sería más el mismo pueblo
porque un día te llevé a él,
y quisiera estar en alguno
donde nada pudiera hacerme recordarte
pero qué cosas pueden no hacerme recordarte.

Sin necesidad de conjeturar si la sintaxis es deliberadamente coloquial o no, cualquier lector nota que resta fluidez al poema, y justo cuando éste debe cerrarse. La dificultad parece generarse porque el penúltimo verso acumula tres verbos seguidos, dos de ellos conjugados con pronombre: "pudiera hacerme recordarte". Además, esto se agrava con la reiteración del último verso ("pero qué cosas pueden no hacerme recordarte").

En cualquier caso, Muertes y maravillas es un libro de madurez; pero es precisamente por el contraste con la limpidez del telón de fondo que estos descuidos llaman la atención. Por lo demás, Teillier fue el primero en detectar y corregir tanto erratas como ripios, y en varios casos ofreció versiones mejoradas de ciertos poemas ${ }^{7}$. Por ejemplo, "Edad de oro" aparece

7 Teillier confiesa: "Rara vez corrijo, prefiero escribir varias versiones, para elegir una, en la cual trabajo. A veces queda limpia de toda intervención posterior, otras veces empiezo 
en una versión perfectible en El cielo cae con las hojas, pero se enmienda en Muertes y maravillas. Algo parecido ocurre con otros poemas de aquel volumen ("Para cantar", "Cuento de la tarde" y "Twilight") y con varios pasajes de sus primeras obras.

Hay otros ejemplos, quizás menos obvios, pero convergentes. En "Un año, otro año", de El árbol de la memoria, se lee: "los perros saludan a sus amos difuntos / que entran a los salones / a contemplar el retrato / que un día se sacaron en la plaza". Como se ve, estos versos parecen sugerir el coloquialismo de 'sacarse' una foto; pero bien pudo escribir "el retrato / que un día se tomaron en la plaza". Desde luego, hay casos afortunados en que la impropiedad semántica favorece la poeticidad, y por ello son bienvenidos; sin embargo, no parece ser el caso del siguiente verso de Crónica del forastero (III): "[...] Si comes toda la sopa te llevarán al circo". Si el pasaje pretendiera dialogar con un niño adoptando la sintaxis infantil, sería pertinente hablar de "comer" la sopa y no de beberla o ingerirla; pero el contexto de los versos vecinos no parece consentir esa lectura.

Por cierto, huelga reafirmar que la calidad poética de Teillier está muy por encima de ripios o imperfecciones menores, y eso es lo que más importa.

\section{TRASCENDENCIA ECOSISTÉMICA}

Incluso quienes no se cuenten entre sus admiradores más entusiastas bien podrían ponderar la precoz madurez poética de Teillier, hasta ahora inigualada en Chile. En este sentido, el poema "Despedida" resulta paradigmático, pero ya es muy conocido como para citarlo aquí. En compensación, consideremos "Si alguna vez", breve poema que cierra su libro póstumo: En el mudo corazón del bosque (1997, p. 56).

Si alguna vez

mi voz deja de escucharse

piensen que el bosque habla por mí

con su lenguaje de raíces.

a podar y corregir en exceso, quitando espontaneidad" [...] "Pero en realidad, nunca sé en verdad lo que voy a decir hasta que ya lo he dicho" (Muertes y maravillas 1971, p. 19) 
Estos cuatro versos resumen casi toda la obra teillierana. Se percibe de inmediato ese aire ligeramente melancólico, como de quien medita sin dramatismos frente a la muerte. Y si el poeta supo ya desde el primer poema de su primer libro que a veces "las amadas palabras cotidianas pierden su sentido", en su último poema de su último libro confía en que el bosque hablará por él cuando ya nadie lo lea. Resulta notable esa paradójica confianza en la comunicación poética: si bien el poeta prevé que su voz terminará desoída o extinguida, alude a ello como una eventualidad, no como un hecho seguro (la expresión "si alguna vez" sugiere algo posible antes que probable).

Si el poeta cumplió su misión escuchando el bosque y entrando en su misterio, nosotros podemos aprender de ese "lenguaje de raíces" un compromiso también raigal.

\section{COMPLEJIDAD POÉTICA Y EPISTEMOLOGÍA COMPLEJA}

He mostrado con diversos ejemplos que la poesía de Teillier, si bien ofrece un primer plano "sencillo", contiene diversos entresijos e inesperadas antinomias. En un plano formal, sus recursos van más allá del tono "espontáneo" y las metáforas e imágenes "fáciles de comprender", e incluyen también patrones fónicos y rítmicos sutiles y poco estudiados. Asimismo, el plano semántico rebasa el tema de la provincia, ya que la noción de 'frontera' debe entenderse de modo multidimensional y no estrictamente espacial. Por último, el plano ideológico excede con mucho la nostalgia por un paraíso perdido, puesto que también abarca una cosmovisión y valores cercanos a una espiritualidad laica.

Si hasta aquí hemos empleado la noción de 'complejidad' en su sentido habitual (como opuesto a simplicidad), ahora podemos ahondar tal concepto en un sentido más filosófico, aplicando para ello la epistemología de Edgar Morin $(1921)^{8}$. En su abordaje de la complejidad, el investigador francés aboga por una transdisciplinariedad que asuma integrativamente los diversos niveles del conocimiento y la existencia humana. Para acceder al pensamiento complejo, es indispensable superar la simplificación (por útil que en principio resulte) y atender a las interconexiones que articulan los diversos niveles o dimensiones. Así, explicaremos y seguidamente aplicaremos tres principios

$8 \quad$ Sigo principalmente a Edgar Morin (1993), si bien Carlos Reynoso (2007) aporta una crítica razonable. 
de este enfoque que resultan pertinentes: el dialógico, el de recursividad y el hologramático.

1. Morin plantea su principio dialógico no ya como el proceso dialéctico de superar los opuestos, sino más bien como la necesidad de asumir que tales opuestos coexisten sin anularse mutuamente. Apreciar la complejidad requiere "unir nociones antagonistas para pensar los procesos organizadores y creadores en el mundo complejo de la vida y de la historia humana" (Morin 1990). En nuestro caso, el lirismo de Teillier no tiene por qué cegarnos ante su compromiso social; valorar la naturalidad y aparente facilidad no implica desentenderse de sus insospechadas dificultades; su sabia artesanía coexiste además con una lucidez teórica innegable; su repliegue contemplativo no desmiente su señero liderazgo en la cofradía de los poetas láricos. En suma, podemos apreciar la dualidad en el propio seno de la unidad, pues ello es señal de organización compleja.

2. En general, hablamos de recursividad cuando en un sistema se repite un patrón en niveles superiores (suprasistema) o inferiores (subsistemas), de modo que lo que era efecto puede volverse causa y viceversa; vale decir, captar recursiones implica superar la causalidad lineal (que revela más bien limitaciones de quien percibe antes que la supuesta simplicidad de lo percibido). Así, ciertos versos iniciales preanuncian el poema al que pertenecen; al mismo tiempo, ese poema es "representativo" del libro, y a su vez ese libro tempranero preanuncia y condensa in nuce lo sustancial de la poesía completa del autor. Pero despreciaríamos la complejidad al preguntarnos si los primeros poemas "generaron" la obra posterior o si, al revés, es por la obra total que esas primeras 'formas' nos parecen representativas del todo. Si ya desde el primer verso del primer libro Teillier declara su compromiso con "las amadas palabras cotidianas", y ese compromiso reaparece en el último poema y "su lenguaje de raíces", ¿cómo no ver en ello un gesto performativo y recursivo, que generó desde el inicio la identidad raigal del poeta? Así se cierra el círculo: el "producto" (primer poema) re-cursa actuando ahora sobre quien lo produjo (poeta).

3. De acuerdo al principio hologramático, resulta tan inadecuado el holismo (énfasis en el todo) como el reduccionismo (énfasis en las partes), ya que lo relevante es captar simultáneamente lo uno y lo otro; por ejemplo, la biología nos ha enseñado que un organismo vivo es un todo, pero cualquiera de sus células permitiría clonarlo, pues esa parte ínfima contiene la carga genética completa. Pues bien, si leemos hologramáticamente la poesía 
de Teillier, descubriremos el todo en la parte y la parte en el todo, como de hecho hemos venido comprobando en estas páginas. En términos comparativos, cabría incluso preguntar: ¿existe otro poeta hispanoamericano tan "hologramático" como Teillier?

Para profundizar más en esta visión "epistemopoética" de la complejidad, leamos un último poema a la luz de los tres principios del pensamiento complejo:

Bajo una misma lámpara

unos escriben poemas

otros falsifican moneda.

[1] Notemos en primer lugar que el poema convoca "dialógicamente" (en el sentido de Morin) a los opuestos: el fraude de falsificar dinero resulta antinómico con la inocencia de hacer versos, pero ambas actividades coexisten (no es casual que el poeta las nombre en versos consecutivos). [2] Paradójicamente, el poema destaca también lo engañoso del contraste, pues tanto el falsificador como el poeta parecen "igualmente" solitarios e incluso operan "bajo una misma lámpara". En cierto modo, el uno necesita al otro para contrastar y reforzar su identidad: el falsificador no "pierde su tiempo" haciendo versos, y el poeta no emplea el suyo en una actividad tan fraudulenta como falsificar dinero. [3] Sin embargo, leído hologramáticamente, el poema sugiere que la sociedad como un todo contiene estos polos opuestos, y que ellos cohabitan "dialógicamente": mientras el falsificador se esmera con prolijidad de artista en lograr que el dinero auténtico y el falso se confundan, el poeta procura hacer verosímil lo ficticio y "perceptible" lo imaginario.

He aquí entonces un epigrama implícitamente sociocrítico: apoyándose en la asonancia entre moneda y poema $(o-e-a)$, insinúa que nuestra sociedad no distingue bien entre un delito (falsificar moneda) y un arte (hacer versos), confundiendo así mímesis falsificadora y mímesis creadora. Paradójicamente, también podemos sobreentender lo opuesto, ya que al presentar una realidad sin juzgarla, estos tres versos insinúan cierta equivalencia entre el falsificador de moneda y el poeta. Al fin y al cabo, somos congéneres y cohabitamos en idéntica oscuridad; compartiendo "una misma lámpara", quizás podríamos coevolucionar.

Examinemos una última paradoja: la poesía de Teillier es traducida al inglés (por Mary Crow en 1990, por Carolyne Wright en 1993), las reediciones atraen nuevos lectores tanto en su patria como fuera de ella, 
e incluso va incrementándose el caudal de los estudios atentos y aun del registro oral ${ }^{9}$; sin embargo, dentro del país, para los poetas jóvenes actuales no es un referente tan clave como lo fue para las promociones de los años sesenta, setenta y ochenta. Al parecer, aquí opera un prejuicio según el cual "un buen poeta reflexiona sobre el lenguaje", y ocurre que en Teillier dicha reflexión suele ser implícita y no inmediatamente notoria. Por otra parte, su aparente redundancia frustra las expectativas de lectores "novedoseros", y su voluntad de arraigo desafía la "desterritorialización" posmoderna. Sin embargo, leída con atención, su lírica posibilita una comprensión "dialógica" (no binaria) de varios contrapuntos: centro versus periferia, aventura versus orden, contemplación lírica versus participación comprometida.

Para expresar en inglés la idea de poeta lárico, Teresa Stojkov tituló su ensayo Jorge Teillier, poet of the hearth. Propongo intervenir con una diagonal la última palabra: $h / e a r t h$ ('fogón'), para condensar así la compleja dialéctica entre "hogar" y "tierra", horno familiar y bosque, aldea y planeta, "larismo" y "lirismo". De paso connotaríamos el interés planetario de un poeta supuestamente aldeano, cuya obra es un puente colgante entre lo local y lo global, y cuya vigencia deviene insospechadamente "glocal"10.

\section{BIBLIOGRAFÍA}

Binns, Niall. La poesía de Jorge Teillier: la tragedia de los lares. Concepción: Ediciones Lar (Literatura Americana Reunida), 2001.

Giordano, Jaime. "La poesía de Jorge Teillier”. En Carlos Cortínez y Omar Lara (comps.): Poesía chilena (1960-1965). Santiago: Ediciones Trilce / Editorial Universitaria, 1966, pp. $114-126$.

"Jorge Teillier: en el umbral de la ilusión". Dioses, antidioses. Ensayos críticos sobre la poesía hispanoamericana. Santiago: LAR, Santiago, 1987, pp. 289-307.

9 Tres libros registran su oralidad: [1] Olivares, Carlos: Conversaciones con Jorge Teillier. Santiago: Editorial Los Andes, 1993. [2] Fuenzalida, Daniel (comp.): Entrevistas (1962-1996). Santiago: Quid Ediciones, 2001; prólogo de Leonardo Sanhueza. [3] Ortega Parada, Hernán: Jorge Teillier. Arquitectura del escritor. Entrevista inédita. Ensayo. Santiago: Lom Ediciones, 2004.

10 El neologismo glocal (introducido en 1992 por Roland Robertson) denota la tensión y la posible síntesis entre lo global y lo local. Ver Josepa Cucó i Giner: "Global y local", en Ascensión Baragaño et al. (dirs.): Diccionario de relaciones interculturales. Diversidad y globalización. Madrid, Complutense, 2007, 162-165. 
Morin, Edgar. Introducción al pensamiento complejo. Barcelona: Gedisa, 1990.

Reynoso, Carlos. Edgar Morin y la complejidad: elementos para una crítica. http://txtantropologia. files.wordpress.com/2007/10/carlos-reynoso-edgar-morin-y-la-complejidad-2007.pdf

Stojkov, Teresa R. Jorge Teillier, poet of the hearth. Londres: Rosemont Publishing \& Printing Corp., Associated University Presses, 2002.

Teillier, Jorge. Para ángeles y gorriones. Santiago: Ediciones Puelche, 1956.

El cielo cae con las hojas. Santiago: Ediciones Alerce / Editorial Universitaria, Santiago, 1956.

El árbol de la memoria. Santiago: Talleres Gráficos de Arancibia Hermanos, 1961.

Poemas del país de nunca jamás. Santiago: Talleres Gráficos de Arancibia Hermanos, Colección El viento en la llama, 1963.

Los trenes de la noche y otros poemas. Santiago: Ediciones de la Revista Mapocho de la Biblioteca Nacional, 1964. Separata de 100 ejemplares.

Poemas secretos. Santiago: Ediciones de los Anales de la Universidad de Chile, 1965. Separata de 50 ejemplares.

Crónica del forastero. Santiago: Talleres Gráficos Arancibia Hermanos, 1968.

Muertes y maravillas. Santiago: Editorial Universitaria, 1971, 162 pp. Colofón de Alfonso Calderón (“Aproximaciones a la poesía de Jorge Teillier”, pp. 150-154).

Para un pueblo fantasma. Valparaíso: Ediciones Universitarias de Valparaíso, 1978

[22004], 142 pp. Prólogo de Enrique Lafourcade: "La casa muerta”, pp. 9-14.

Hotel nube. Concepción: Ediciones LAR, 1996.

Los dominios perdidos. Santiago: Fondo de Cultura Económica, 1992. Selección de Erwin Díaz; prólogo de Eduardo Llanos (“Jorge Teillier, poeta fronterizo”, pp. 9-15).

Crónica del forastero. Selección y prólogo (pp. 7-14) de Jaime Valdivieso. Buenos Aires: Editorial Colihue, 1999.

El árbol de la memoria y otros poemas. Santiago: LOM Ediciones, 2000. Selección y prólogo de Pedro Lastra ("Sobre Jorge Teillier”, pp. 5-9).

El árbol de la memoria. Antología poética. Madrid: Huerga y Fierro Editores, 2000. Selección y prólogo de Niall Binns ("La tragedia de los lares", pp. 9-19).

Prosas. Santiago: Editorial Sudamericana, 2000. Recopilación, prólogo y anotaciones críticas de Ana Traverso.

Poemas del país de nunca jamás. Crónica del forastero. Santiago: Tajamar, 2003. Prólogo de Niall Binns (“1963: el bosque, el libro y la tierra baldía”, pp. 7-16).

El cielo cae con las hojas. El árbol de la memoria. Los trenes de la noche. Santiago: Tajamar, 2004. Prólogo de Federico Schopf ("Marginalidad y utopía en la poesía de Jorge Teillier", pp. 7-24).

From the Country of Nevermore. Selected poems of Jorge Teillier. Translated and with an introduction of Mary Crow. New England: The University Press of N. E., 1990.

In order to talk with the dead. Selected poems of Jorge Teillier. Translated and with an introduction of Carolyne Wright. Texas: University of Texas Press, 1993. 